\title{
Addressing Muddy Points Early in the Semester Increases Student Learning in a Bioinstrumentation Laboratory Course
}

Dr. Renata Fortuna Ramos, Rice University

Renata Ramos is the Director of Undergraduate studies and a Lecturer in the Department of Bioengineering at Rice University, 6100 Main St., Houston, TX 77005: rfr1@ rice.edu 


\title{
Addressing Muddy Points Early in the Semester Increases Student Learning in a Bioinstrumentation Laboratory Course
}

\begin{abstract}
Many lecture courses use muddy points as an instructional assessment technique that allows the instructor to gather information about the topics that are not clear to the students at the end of each class. Using this information, the amount of lecture time allocated to a specific topic can be increased or decreased to match students' feedback and emphasize the areas where the students need more support.
\end{abstract}

A modified version of this technique was recently implemented in a junior level, project-based bioinstrumentation course that focuses around the design, construction and testing of biomedical technology. At the end of each class, students take an on-line survey where they are asked to identify the concepts that are still unclear and/or to highlight the information and tools they need in order to successfully complete their projects. Due to the fact that this is an open-ended laboratory course and that the amount of lecture time is minimal, the muddy points were too diverse and could rarely be addressed during class time. Instead of using muddy points to modify the class content, a written document was developed covering all the questions asked by the students and providing them with resources to different tools and material that would help them obtain the additional information they needed. These feedback documents were posted within a week after the students' comments were collected and were available until the project was completed.

The impact of implementing this technique was assessed using final project grades. The first project was selected to evaluate these changes since it is graded individually and can better address student learning. Oral project presentations and written report grades were compared before and after 2013 when this technique was first used in the course. Average presentation and report grades show an increase after muddy points were introduced to the laboratory course, suggesting that addressing misconceptions and providing feedback early on contributes to student learning in the bioinstrumentation laboratory course.

Classroom Assessment Technique: Muddy Points

There is strong evidence showing not only that effective feedback can improve student learning; but also that receiving relevant feedback in a timely manner is crucial to the learning process ${ }^{1-5}$.

Classroom assessment techniques are widely used to obtain information on the success of the learning process. As instructors, we often make the mistake of assuming that students are learning everything we teach them in the classroom. Assessment techniques help us determine how well the students are actually learning the material, while at the same time provide us with the information required to continuously make modifications that will help improve student learning and/or teaching effectiveness ${ }^{6}$. 
There are several assessment techniques that can be used in the classroom such as knowledge probe, minute paper, misconception check, attention quiz, etc. ${ }^{7}$. One of the most widely known classroom assessment techniques is known as muddy points, in which the students are asked to write down the concept(s) that they found most confusing during that class period.

Many large lecture courses use muddy points as an instructional assessment technique that allows the instructor to gather information at the end of the class about the topics which are not clear to the students. Using this information, the amount of lecture time allocated to a specific topic can be increased or decreased to match students' feedback and emphasize the areas where the students need more support ${ }^{8}$. This technique offers a two-way feedback mechanism in which the students provide feedback to the instructor with respect to their learning concerns and the instructor provides feedback to the students addressing their learning concerns ${ }^{9,10}$.

The assessment technique described above allows the instructor to determine how well the students are learning and what areas are still unclear. By collecting muddy points at the end of each class and using the information to emphasize the specific topics that the students have identified as weak knowledge areas, the instructor can provide immediate and relevant feedback.

\section{Description of the Bioinstrumentation Laboratory Course}

The Bioinstrumentation Laboratory Course (BIOE 385) is a required junior-level course for bioengineering students. The course typically enrolls $40-50$ students and is offered every fall semester. In order to maintain the number of students to a minimum, this course is divided into smaller groups called sections (3 sections per week). All the sections cover the same topic at any given week, but different students attend lab on a different day (Monday, Tuesday, or Thursday).

The objectives of this course are:

1. To design, build and troubleshoot electrical circuits to acquire biological measurements.

2. To analyze and process acquired data and present it in a user-friendly manner.

3. To analyze electrical signals from humans and interpret these physiological measurements.

4. To solve open-ended engineering design projects taking into consideration resources and design criteria requirements.

5. To justify their final engineering decisions and present their design in a written document.

6. To identify and overcome sources of error and challenges which arise from the interaction between living and non-living systems.

The Bioinstrumentation laboratory course is an open-ended, project-based course structured around designing, building and testing two different devices: and optical immunoassay and an electromyogram-reflex device. The optical immunoassay project is the focus of this research and consists of developing inexpensive point of care diagnostic systems for use in the developing world. The students are tasked with building and testing possible circuit designs and the associated LabView program that can be used as a preliminary optical immunoassay device.

The Bioinstrumentation laboratory course is formatted so that groups of 2-3 students work together in order to achieve a set of goals every week (Table 1). The class starts with a mini 
lecture (10-15 minute long) that provides the students with the background necessary to achieve the weekly goals and the rest of the time is used by the students to work on their prototypes.

Table 1. Sample schedule for the Optical Immunoassay prototype. Students are required to achieve specific goals every week in order to complete the device requirements on time. Progress is evaluated weekly as complete or incomplete.

\begin{tabular}{|c|c|}
\hline Session & Prototype \\
\hline 1 & Circuits Review, NI ELVIS \\
\hline 2 & Hardware: Design and Build \\
\hline 3 & Software \\
\hline 4 & Test, Modify and Finalize Prototype \\
\hline 5 & Prototype Evaluation \\
\hline
\end{tabular}

The optical immunoassay device was evaluated using a prototype demonstration and a written technical report:

1. The prototype demonstration (50 points) consisted of a 10-15 minute oral presentation where each student met individually with the instructor to explain and justify the technical decisions made by their team, and a device performance evaluation that assessed the accuracy and quality of the prototype.

2. The written technical report (50 points) was an individual assignment that consisted of 5 sections: executive summary, goals and methods, technical description of the work, testing and results, and future recommendations. Together, these assignments evaluate the students' technical knowledge and the quality of the group project.

Implementation of Muddy Points to BIOE 385

A modified version of the muddy points technique described above was implemented in the bioinstrumentation laboratory course. At the end of each class, students take an on-line survey via a Collaboration and Course Management system where they are asked to identify the concepts that are still unclear and/or to highlight the information and tools they need in order to successfully complete their projects. The surveys are anonymous, but completion is required and counts towards the final grade.

Due to the fact that this is an open-ended laboratory course and that the amount of lecture time is limited, the collected muddy points were too diverse and could rarely be addressed during class time. Instead of using the muddy points to modify the class content or to focus the lecture material, a written document was developed that the students could access any time during the semester. 
After collecting feedback from all the students registered for any of the three course sections, the comments were grouped by topic and a document was developed to address all the muddy points identified by the students. Furthermore, additional resources (such as links to different tools, online tutorials and written materials) were also provided to help the students obtain a more indepth technical knowledge related to these topics. These feedback documents were posted within a week after the students' comments were collected and were available until the project was completed. Since the class only meets once per week, the feedback was collected after each section on Monday, Tuesday and Thursday and was made available to the students before the following class period.

\section{Evaluation of Changes Introduced to BIOE 385}

The impact of implementing the muddy points technique was assessed using final project grades. The first project, the optical immunoassay, was selected to evaluate these changes since it is graded individually and can better address student learning. Prototype demonstrations and written technical report grades were used to evaluate the effect that muddy points used as an immediate feedback mechanism had on student learning.

Prototype demonstrations and written technical report grades were compared two years before (2011, 2012; n=98) and two years after (2013, 2014; n=93) this technique was first introduced in the course (Figure 1). A one-tail, unpaired student's t-test showed a statistically significant increase $(\mathrm{p}=0.005)$ in the final prototype demonstration grades from $34.9 \pm 7.1$ before introducing muddy points to the course to $37.7 \pm 6.6$ when muddy points were used.

Additionally, written technical report grades were compared before and after muddy points were introduced to the laboratory course in 2013 using a one-tail unpaired student's t-test (Figure 1). Using the same grading rubric every academic year, written technical reports showed a statistically significant increase $(\mathrm{p}=0.005)$ after muddy points were introduced $(35.1 \pm 6.9$ compared to $37.9 \pm 6.8$ ).

Although the direct impact that implementing muddy points had on each individual student cannot be directly measured, qualitative observations from the instructor during the prototype demonstrations and written technical reports in 2013 and 2014 strongly suggest that these changes helped the students gain a more in-depth understanding of the technical knowledge. The instructor reported that after muddy points were introduced to the course the students had a better grasp of the technical material and were able to better justify their engineering decisions and answer questions in the individual oral presentations and written technical reports. Even though these observations are qualitative in nature, they support the theory that addressing misconceptions and providing relevant feedback early on can contribute to student learning in the BIOE 385 laboratory course. 


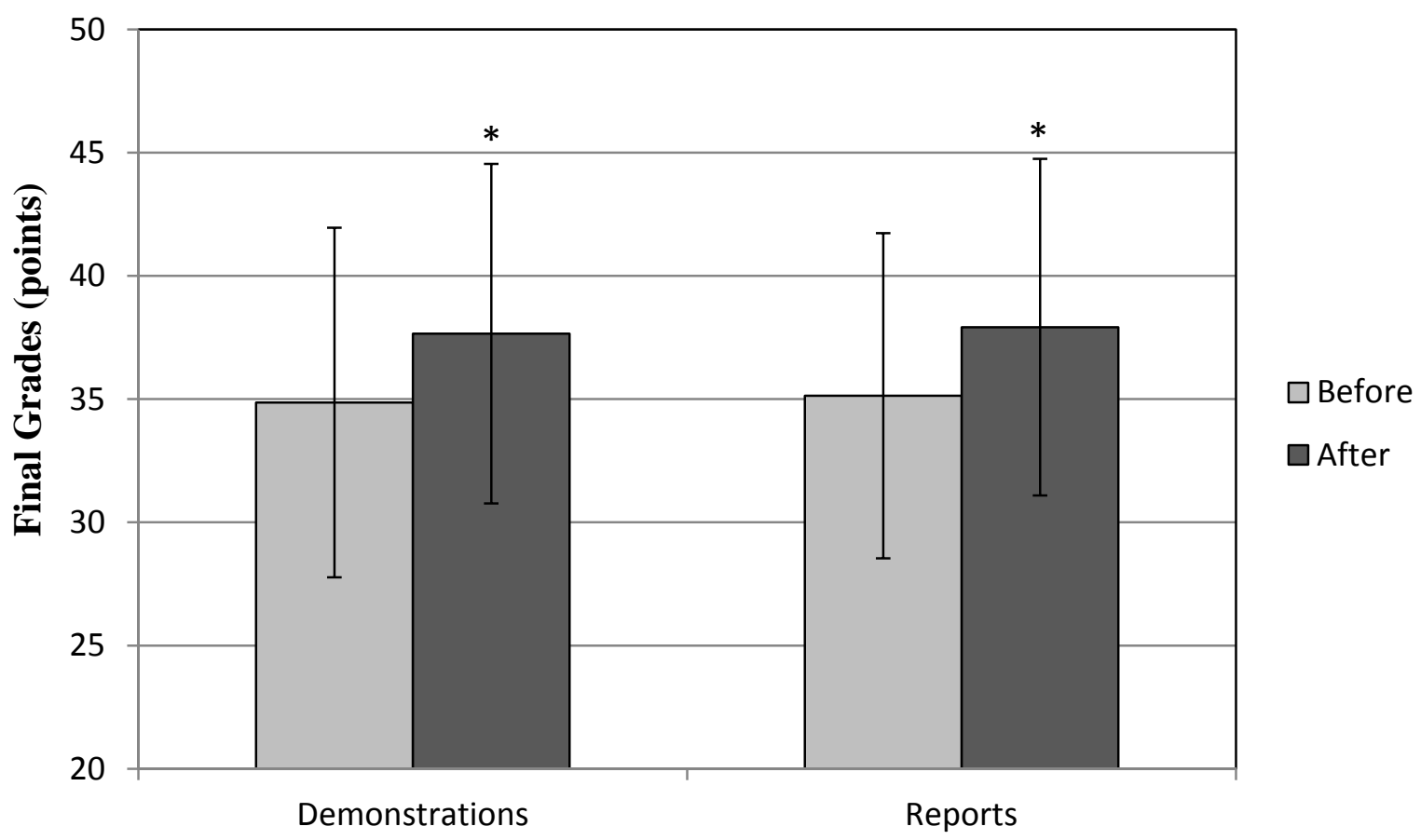

Figure 1. Average grades for prototype demonstrations and technical reports show a statistically significant increase $\left({ }^{*} \mathrm{p}<0.01\right)$ after the introduction of muddy points. Data represents mean \pm standard deviation of assignment grades for all the students registered for BIOE 385 before (2011, 2012; n=98) and after (2013, 2014; n=93) muddy points were introduced. Final grades are shown using a 50 point scale.

In 2014, the online activity of the 43 students registered for the course was monitored using the Collaboration and Course Management system in order to determine how many times each feedback document (laboratory sessions 1-6) were accessed by the students. The number of times each feedback document was accessed online (Figure 2) was used to determine if the students were reading these documents while working on their projects, reports and/or studying for their oral presentations. These results show that the feedback documents were in fact accessed by the students and that the documents created for sessions one through five were accessed more times than the number of students that were registered for the course (session 1 : 77 times, session 2: 59 times, session 3: 50 times, session 4: 58 times, session 5: 50 times, session 6: 37 times). 


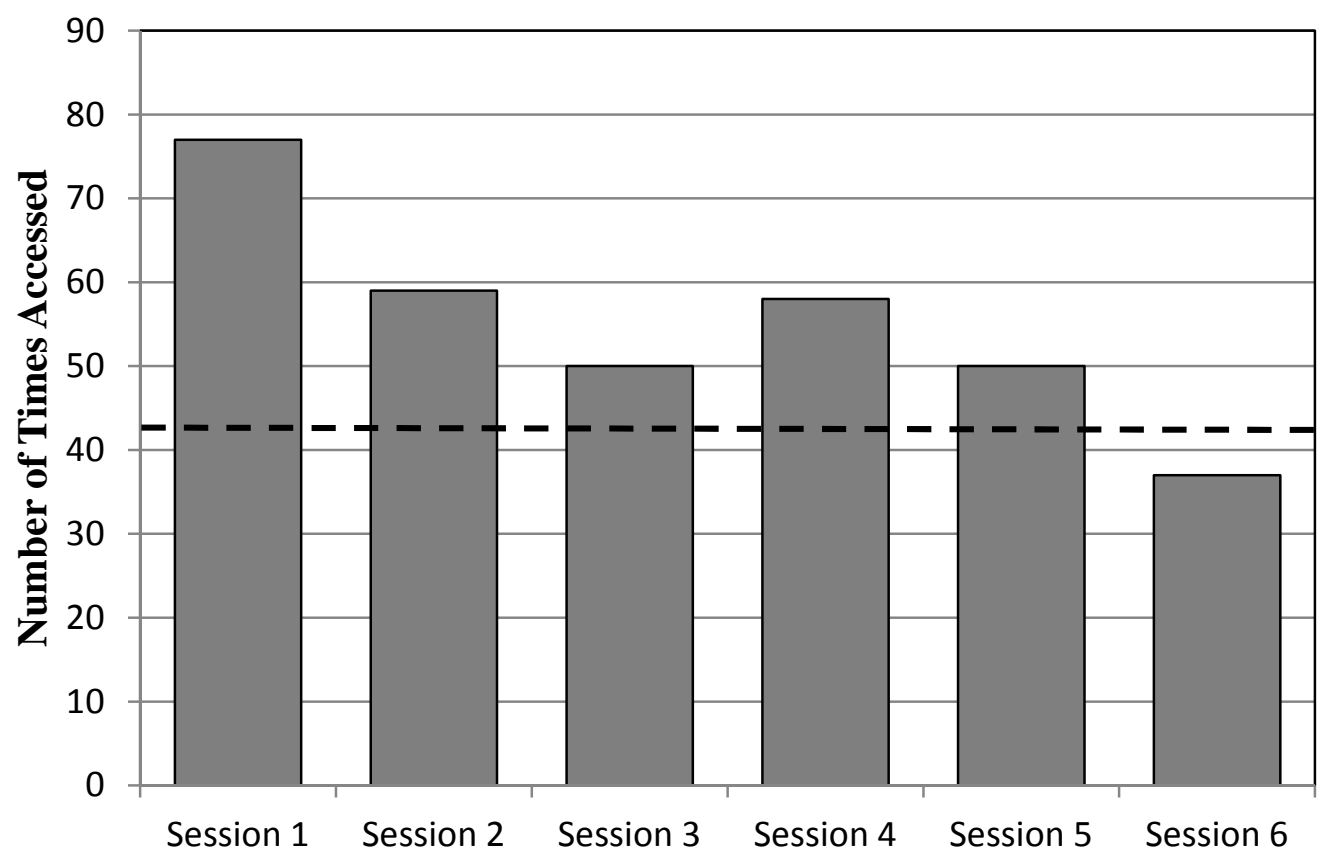

Figure 2. The number of times that the feedback documents from sessions one to five were accessed during the semester is greater than the number of students registered for the course represented by the dotted line. Data collected from 43 studetns registered for the course in 2014.

\section{Discussion and Future Work}

These results show that the introduction of muddy points as a feedback mechanism increases the average laboratory project grades of students in the junior-level Bioinstrumentation laboratory course. This grade increase can be seen when comparing the average grades of both prototype demonstrations and written technical reports before and after $2013(\mathrm{p}<0.01)$. Even though the observed changes are small in magnitude, the increase in prototype demonstration grades indicates that muddy points helped the students to be able to explain their devices better (represented by the individual oral presentations and technical reports), while at the same time contributed to improving group performance (device performance evaluation grades were also increased. Altogether, the observed increase in average grades suggests that addressing misconceptions and providing relevant feedback in a timely manner contributes to student learning in this laboratory course.

The results also show that the number of times the feedback documents were accessed is greater than the number of students registered for the course. These numbers suggest that the feedback documents contributed to the increase in grades observed above; however there is no way to determine which students accessed them or if the students that accessed the documents were the ones that performed better in the course. Since students work in pairs during lab time and share one computer per group and since the documents could be downloaded outside of class and accessed without going back to the web source, it is also possible that the number of times the documents were read by the student is higher than the one reported in this paper. 
One of the difficulties of implementing muddy points in a project-based laboratory course is that several of the students' questions can be specific to their project and do not apply to every student in the class. Although students were instructed to use this assessment tool to discuss only general concepts, it was common to find some of the questions to be specific to one team's prototype (especially during the final weeks when students were working on the software part of the project). This concern was addressed in two different ways: (1) since the Collaboration and Course Management system used to collect anonymous feedback had the option of replying to an individual comment, the instructor was able to answer some of these individual questions directly; and (2) by encouraging the students that did not receive a direct answer to their questions to email the instructor and/or schedule a meeting to discuss their project in more detail. It is hard to measure the level of success obtained when answering the specific questions, but several students did schedule individual appointments with the instructor afterwards.

Although creating the feedback documents do require the instructor to invest extra time and work during the semester, they do not have any financial cost associated with them and the material created can be reused in future semesters. In addition to the regular time spent preparing and teaching this course before 2013, the instructor spent approximately 5-8 extra hours/week reading the students' muddy points, answering their questions and finding extra resources, tools and material that would help them obtain the additional information they needed. Creating the feedback documents in 2013 required considerable effort; however, in 2014 the instructor spent less than 2 hours/week to update them since a lot of the material could be reused from the previous year.

Before implementing this technique in 2013, the instructor spent a significant amount of time meeting with individual students and responding to emails. After this technique was implemented the students could often find the answer to several of their questions by reading the feedback documents, therefore reducing the need for individual meetings with the instructor. One clear advantage of providing these feedback documents to the entire class and making them available throughout the semester is that the students can learn from their classmates by reading what others have identified as muddy points. Additionally, by analyzing which muddy points appear repeatedly, the instructor can gather information on the topics that the students are struggling with and use it in the future to update the lecture material and protocols in order to address the misconceptions even before they appear.

Implementation of the muddy points feedback technique described above considerably improved the quality of BIOE 385 by helping the students gain a more in-depth understanding of the technical material necessary to complete their laboratory projects. The changes described above can be implemented in most courses that require a strong technical knowledge or that require students to have a strong understanding of the concepts learned before continuing to the next topic.

\section{Bibliographic Information}

1. Nicol, D.J., and Macfarlane-Dick, D. (2006) Formative Assessment and Self-Regulated Learning: a Model and Seven Principles of Good Feedback Practice. Studies in Higher Education. 31 (2), pp. 199-218 
2. Black, P., and Wiliam, D. (1998) Assessment and Classroom Learning. Assessment in Education. 5 (1), pp. 774

3. McTighe, J. and O’Connor, K. (2005) Seven Practices for Effective Learning. Educational Leadership, Association for Supervision and Curriculum Development. 63, pp. 10-17

4. Choy, S.J., McNickle, C., and Clayton, B. (2002) Learner Expectations and Experiences. Student Views of Support in Online Learning. National Centre for Vocational Education Research. pp. 106-122

5. Hattie, J., Timperley, H. (2007) The Power of Feedback. Review of Educational Research. 77 (1), pp. 81-112

6. Shaeiwitz, J.A. (1998) Classroom Assessment. Journal of Engineering Education. 87 (2), pp. 179-183

7. Cross, K.P., Angelo T.A. (1993) Classroom Assessment Techniques: A Handbook for College Teachers. Jossey-Bass. San Francisco, CA

8. King, D.B. (2011) Using Clickers to Identify the Muddiest Points in Large Chemistry Classes. Journal of Chemical Education. 88, pp. 1485-1488

9. Carberry, A.R., Krause S.J., Ankeny C.J., and Waters, C. (2013) Unmuddying” Course Content Using Muddiest Point Reflections. Frontiers in Education Proceeding.

10. Krause, S.J., Baker, D.R., Carberry, A.R., Alford, T.L., Ankeny, C.J., Maass, S., Koretsky, M., Gibbons, B.J., Brooks, B.J., Gilbuena, D.M., Waters, C., Stuart, J. (2014) Characterizing and Assessing Student Learning Issues and Misconceptions (SLIM) with Muddiest Point Reflections and Fast Formative Feedback. American Society of Engineering Education. Indianapolis, IN. Reference: 10445 